\title{
PRODUÇÃO DE VIDEIRA 'SUPERIOR SEEDLESS', CULTIVADAS EM DIFERENTES TENSÕES DE ÁGUA NO SOLO
}

\section{ESSIONE RIBEIRO SOUZA ${ }^{1}$; JOSÉ ANCHIETA DE ASSUNÇÃO PIONÓRIO²; VALTEMIR GONÇALVES RIBEIRO ${ }^{3}$ e SÉRGIO OLIVEIRA PINTO DE QUEIROZ ${ }^{3}$}

${ }^{1}$ Eng. Agrônomo, MSc. Doutoranda, Bolsista CAPES, Universidade do Estadual Paulista (UNESP). Rua prof. ${ }^{\text {a }}$ Ana Júlia Prado de Oliveira, 4 apt 4, Parque Residencial Jardim primavera, Botucatu, SP/Brasil, Tel: (14) 33544620. CEP 18610-390, essione.r@hotmail.com

${ }^{2}$ Eng. Agrônomo, mestrando do Programa do Pós-Graduação em Horticultura Irrigada da Universidade do Estado da Bahia- UNEB, Email: anchietapionorio@hotmail.com

${ }^{3}$ Engenheiro Agrônomo, Prof $^{\circ}$ D.Sc. do Departamento de Tecnologia e Ciências Sociais, Universidade do Estado da Bahia (DTCS/UNEB), E-mail: vribeiro@uneb.br, sopqueiroz@gmail.com

\section{RESUMO}

O objetivo deste trabalho foi avaliar o número total de cachos por planta e concentração de açúcares totais em ramos de videira 'Superior Seedless' submetidas a diferentes tensões de água no solo. $\mathrm{O}$ delineamento estatístico utilizado foi o de blocos casualizados com 4 tratamentos (a) Testemunha, b) tensão de $70 \mathrm{kPa}$, c) tensão $50 \mathrm{kPa}$, d) tensão de $30 \mathrm{kPa}$, e 6 repetições, sendo cada parcela constituída por duas plantas. Foram determinadas curvas de umidade de solo em laboratório e em campo, fertilidade de gema potencial (realizada sob lupa (aumento: 30 vezes), coletando-se 17 sarmentos no braço primário da planta, contendo 15 gemas cada), fertilidade real (utilizando-se a razão: número de gemas férteis pelo número total de gemas brotadas por planta) e açúcares totais. As condições laboratoriais favoreceram a chegada da tensão a $-70 \mathrm{kPa}$ em apenas 21 dias durante o procedimento de determinação da curva de retenção em laboratório. As diferentes tensões aplicadas ao solo não promoveram diferenças significativas quanto ao número total de cacho por planta. Contudo, a tensão de -30 $\mathrm{kPa}$ apresentou uma redução de $68 \%$ na lâmina de irrigação quando comparado com a testemunha e o percentual de carboidratos nos ramos da videira 'Superior Seedless foi influenciado pelas diferentes tensões de água no solo.

Palavras-chave: Irrigação, manejo, açúcares totais

\section{SOUZA, E. R.; PIONÓRIO, J. A. de A.; RIBEIRO, V. G.; QUEIROZ, S. O. P. de PRODUCTION VINE 'SUPERIOR SEEDLESS' CULTURED UNDER DIFFERENT WATER STRESS CONDITIONS}

\section{ABSTRACT}

The aim of this study was to evaluate the total number of clusters per plant and the sugar concentration of "Superior Seedless" grapevine branches under different soil water tensions conditions. The statistical design was a randomized block with 4 treatments (a) control, b) 70 $\mathrm{kPa}$ tension, c) $50 \mathrm{kPa}$ tension, d) $30 \mathrm{kPa}$ tension, and 6 replications, each plot consisting of two plants. Soil moisture curves were plotted in laboratory and field conditions, potential bud 
fertility (carried out with the help of a 30x magnifier glass and collecting 17 branches in the primary arm of the plant with 15 buds each), actual fertility (given by the fertile buds to sprouted buds per plant ratio) and total sugars. Laboratory conditions helped stress to reach a $70 \mathrm{kPa}$ level in just 21 days during the procedure to determine the retention curve in the laboratory. The different stress levels applied to the soil did not cause significant differences in the total number of clusters per plant. However, a $-30 \mathrm{kPa}$ stress showed a $68 \%$ reduction in water depth when compared to control and different soil water stress affected the carbohydrate percentage in branches of the "Superior Seedless" vine.

Keywords: Irrigation, management, total sugars

\section{INTRODUÇÃO}

A viticultura é uma das atividades agrícolas mais importantes do pólo PetrolinaPE/Juazeiro-BA em termos econômicos e em uso de mão-de-obra. No entanto, todas as cultivares utilizadas foram introduzidas na região nos últimos anos e, portanto, apresentam necessidade de adaptação da base de manejo original (Souza et al., 2012). O conhecimento dos fatores relacionados ao desenvolvimento reprodutivo de cultivares de videira tem grande relevância, porque tem implicação na produção das plantas de videira.

No Vale do São Francisco o regime pluviométrico distribui-se de forma escassa, irregular e concentrada ao longo de quatro meses, tornando as chuvas insuficientes para atender as demandas hídricas da videira que variam de 500 a $1.200 \mathrm{~mm}$ (Sentelhas, 1998; Soares e Costa, 1998), tornando o uso da irrigação indispensável para a sua produção.

Serman et al. (2004), estudando a 'Superior Seedless', irrigada sob diferentes percentagens da evapotranspiração, verificaram diminuição do número de cachos comercializáveis, nos tratamentos com déficit hídrico, apesar de não terem observado diferenças significativas nos sólidos solúveis. No entanto, para Ferreyra et al. (2006), a aplicação de déficit hídrico à 'Crimson Seedless' proporcionou diferenças significativas apenas quanto à produtividade, sobretudo a partir do segundo ciclo de cultivo.

Para Marinho et al. ( 2009) a redução das lâminas e a estratégia de déficit hídrico na fase de maturação da uva 'Superior Seedless', beneficiou a qualidade e produtividade da uva, além de eficiência no uso de água. Já para Silva et al. (2009) a irrigação provoca alterações nas características químicas da uva, reduzindo seus valores, não sendo recomendado seu uso no período de maturação dos frutos.

As tensões de água no solo, segundo Orlov (1985), dependem do tipo de solo e podem variar entre $15 \mathrm{kPa}$ a $25 \mathrm{kPa}$ para solos arenosos e de $40 \mathrm{kPa}$ a $60 \mathrm{kPa}$ para solos argilosos. Klar (1991) recomenda para a videira tensões entre 40 kPa e $100 \mathrm{kPa}$. Conceição et al. (1998), para estimar a demanda hídrica durante o ciclo da cultura de uvas finas na região de Jales, mantiveram tensões entre $6 \mathrm{kPa}$ e $15 \mathrm{kPa}$, ou seja, próximos aos da Capacidade de Campo (Reichardt, 1988), instalando os tensiômetros na profundidade de $0,45 \mathrm{~m}$ para as leituras das épocas de irrigação.

Segundo Deloire et al. (2004), a imposição de um déficit hídrico moderado a videira em determinadas fases fenológicas tem um impacto positivo sobre a concentração de açúcares, acidez pH e compostos fenólicos no mosto. Para Bassoi et al. (2011) a imposição de déficit hídrico em videira 'Syrah' proporcionou maior concentração de açúcares e a redução da acidez nos frutos, contribuindo para a melhoria da qualidade das uvas para vinificação. Portanto, o monitoramento e o manejo da água, associados ao método de 
irrigação adotado têm importância para o bom desempenho dos aspectos quantitativos da produção de uva no Vale do Submédio São Francisco.

O conteúdo de água no solo é fator importante para o desenvolvimento das inflorescências, sendo necessário o seu acompanhamento através de curvas características de umidade, para atender as particularidades físicas de cada tipo de solo, com vista a uma maior produtividade. Deste modo é objetivo deste trabalho avaliar a produção e concentração de açúcares totais em plantas de videira 'Superior Seedless' submetidos a diferentes tensões de água no solo.

\section{MATERIAL E MÉTODOS}

O experimento foi conduzido em parreiral comercial da Fazenda Fruticultura Maria Martins Ltda, no N 2, Petrolina/PE com plantas videiras 'Superior Seedlees', plantadas em espaçamento $3,0 \times 2,5 \mathrm{~m}$, conduzidas no sistema tipo latada e irrigada por gotejamento, com gotejadores espaçados de $0,5 \mathrm{~m}$ na linha de plantio, com vazão de $2,5 \mathrm{~L} / \mathrm{h}$. Antes da instalação dos tensiômetros foi feita análise física e química do solo.

Foram determinadas curvas de umidade de solo em laboratório e em campo, com intuito de comparar os resultados para assim definir a lâmina de irrigação a ser aplicada nas diferentes tensões. Os tensiômetros passaram por fase de teste segundo metodologia de Libardi (1999), para verificar se estavam em perfeito estado de funcionamento.

Depois da fase teste, os tensiômetros foram instalados em 2 vasos com volume de $13,810 \mathrm{~L}$ preenchidos com solo extraído da propriedade, nas profundidades de 0-20 e 20-40 $\mathrm{cm}$, assim, foram retiradas $200 \mathrm{ml}$ para fazer análise física do solo para cada uma das profundidades.

Em seguida o solo foi colocado sobre a lona de plástico para secar (Terra Seca Fina ao ar = TSFA) por 24 horas, depois destorroado e peneirado, para determinação da curva característica de umidade do solo em laboratório.

Fez-se um orifício na lateral em cada vaso para colocar o tensiômetro de $0-10 \mathrm{~cm}$, e em sua base, fez cinco orifícios para drenagem da água, sob esses orifícios foi colocado papel filtro para evitar perda de solo. Em seguida o solo (TFSA) foi colocado nos baldes e os oitos tensiômetros cheios de água destilada, fervida e fria instalados, sendo que foram distribuídos quatro tensiômetros por vaso, onde o de $0-10 \mathrm{~cm}$ foi colocado na lateral e os de $0-20$ no centro, na vertical sob a TFSA, em seguida foram colocados em um recipiente contendo água para que ocorresse ascensão da água por capilaridade. Quando o solo atingiu a capacidade de campo, fizeram-se leituras das tensões com Tensímetro Digital de Punção (TDP) e para todas as leituras obtinha-se o peso do solo. Essas leituras e pesagem duraram um período de 21 dias no intervalo de 24 horas, para se determinar o coeficiente de umidade (Figura 1). 


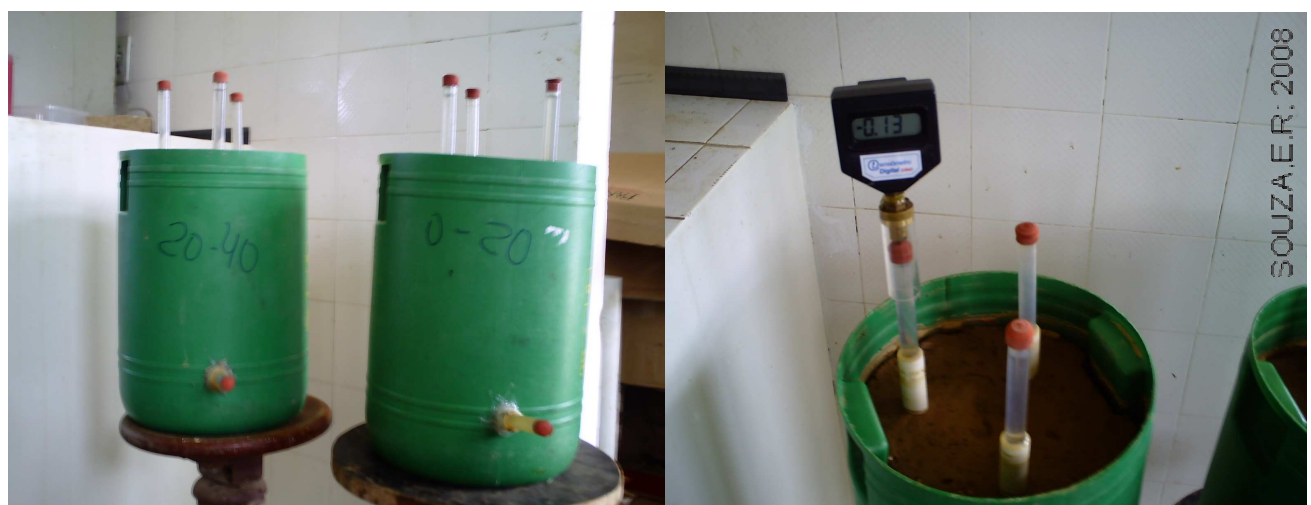

Figura 1. Determinação da curva característica de umidade do solo pelo método da tensiômetria em laboratório.

Conforme descrito por Marouelli (1996), foi instalada bateria de nove tensiômetros em $1 \mathrm{~m}^{2}$, em condições de campo, para determinação da curva característica de umidade de solo, nas profundidades de 0-20;20-40 e de 40-60 cm, levando em consideração as condições heterogêneas do campo, onde para cada leitura de tensão, eram retirada amostra do solo nas diferentes profundidades e devidamente embalada foram levada para o laboratório, para determinação de peso seco, e assim para cada leitura obtinha-se um valor da umidade volumétrica. Os dados obtidos foram comparados com a curva determinada em laboratório apenas nas profundidades de 0-20 e 20-40 cm (Figura 2).

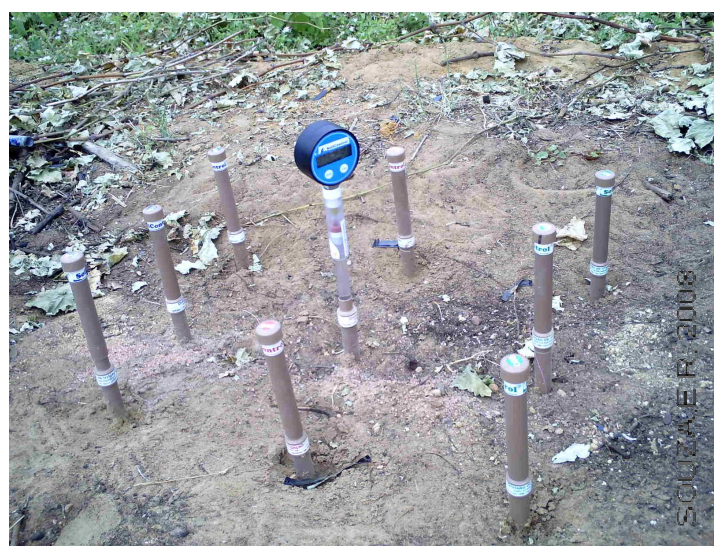

Figura 2. Determinação da curva característica de umidade de solo segundo metodologia de Marouelli (1996).

O delineamento experimental utilizado foi blocos ao acaso, quatro tratamentos, três tensões indicativas para a recarga hídrica por irrigação $(-30,-50$ e $-70 \mathrm{kPa})$ e testemunha e seis repetições e duas plantas por parcela. A testemunha foi o manejo de irrigação adotado na propriedade irrigando-se $7 \mathrm{~mm} /$ dia.

Após determinadas às curvas de umidade do solo instalaram-se tensiômetros nas profundidades de 0-20, 20-40, 40-60, realizando leituras diárias (às $07 \mathrm{~h}$ e às $16 \mathrm{~h}$ ) com Tensímetro Digital de Punção (TDP) até chegar à tensão de $-30 \mathrm{kPa}$ (com intervalo de 3 dias entre uma lâmina e outra). Todas as lâminas de irrigação foram determinadas pelo valor de umidade referente à tensão lida no tensiômetro para as diferentes tensões, subtraída da umidade correspondente à capacidade de campo $(-10 \mathrm{kPa})$. 
O manejo da irrigação foi baseado na curva característica de retenção determinada tanto em campo como em laboratório, obtida no perfil de zero até $40 \mathrm{~cm}$ de profundidade do solo (Figura 3 e 4). Segundo Santos et al. (2002) é nesta faixa que se encontra a maior quantidade de raízes da videira.

Quando as plantas estavam na fase de algodão (15 dias depois da poda de produção) foram submetidas a uma restrição hídrica até os limites preestabelecidos de $-30,-50$ e $-70 \mathrm{kPa}$, quando ocorreu a recarga hídrica por irrigação para o retorno à capacidade de campo (-10 $\mathrm{kPa})$.

A análise de fertilidade de gemas potencial foi realizada sob lupa (aumento: 30 vezes), coletando-se 17 sarmentos no braço primário da planta, contendo 15 gemas cada. No ramo foi determinada fertilidade potencial nas porções basal (0-5 gemas), intermediária (6-10 gemas) e apical (11-15 gemas), conforme metodologia aplicada por Ribeiro et al. (2008). Após 27 dias da data da poda de produção (com os sarmentos podados com 10 gemas, a fertilidade real foi avaliada em todos os sarmentos, utilizando-se a razão: número de gemas férteis pelo número total de gemas brotadas por planta).

Para determinação de açúcares totais, foram retiradas amostras de ramos das plantas submetidas às diferentes tensões. As análises de carboidratos foram executadas seguindo a metodologia de extrações de glicídios totais em glicose conforme metodologia descrita pelo instituto Adolfo Lutz (1985).

O delineamento estatístico utilizado foi o de blocos casualizados com 4 tratamentos e 6 repetições, sendo cada parcela constituída por duas plantas. As médias foram comparada pelo Teste de média Tukey a 5\% de probabilidade.

\section{RESULTADOS E DISCUSSÃO}

$\mathrm{Na}$ Tabela 1 observa-se que solo apresenta textura arenosa, característico da região do Submédio São Francisco, e que os teores de nutrientes são variáveis (a, b, c, d). O que pode ser justificado pela adubação realizada a cada ciclo vegetativo na cultura da videira.

Tabela 1. Análise física e química do solo da área experimental, Petrolina/PE.

\begin{tabular}{|c|c|c|c|c|c|c|c|c|c|}
\hline Horizonte & $\begin{array}{l}\text { Compc } \\
(\mathrm{g} / \mathrm{kg})\end{array}$ & ção gra & ométrica & $\begin{array}{l}\text { Água dispersa } \\
(\mathrm{g} / \mathrm{kg})\end{array}$ & $\begin{array}{l}\text { Textura } \\
\text { em laboratório }\end{array}$ & \multicolumn{4}{|c|}{ Densidade $\left(\mathrm{g} / \mathrm{cm}^{3}\right)$} \\
\hline $\begin{array}{l}\text { Profundidade } \\
(\mathrm{cm})\end{array}$ & Areia & Silte & Argila & & & Solo & \multicolumn{3}{|c|}{ Partícula } \\
\hline $0-20$ & 803 & 181 & 16 & 24 & Areia franca & 1,27 & \multicolumn{3}{|c|}{2,24} \\
\hline $20-40$ & 902 & 84 & 14 & 8 & Areia & 1,4 & \multicolumn{3}{|c|}{2,2} \\
\hline $40-60$ & 854 & 116 & 30 & 11 & Areia franca & 1,45 & \multicolumn{3}{|c|}{2,27} \\
\hline \multicolumn{10}{|c|}{ Análise química do solo } \\
\hline Ext. Sat & $\mathrm{g} / 100$ & $\mathrm{~g} / 100$ & $\mathrm{pH}$ & \multicolumn{2}{|l|}{$\mathrm{Mg} / \mathrm{dm}^{3}$} & \multicolumn{4}{|c|}{$\mathrm{Cmol}_{\mathrm{c}} / \mathrm{dm}^{3}$} \\
\hline C.E $/ 25^{\circ} \mathrm{C}$ & Mat & $\mathrm{C}$ & $\mathrm{H}_{2} \mathrm{O}$ & \multirow[t]{2}{*}{$\mathrm{P}$} & $\mathrm{K}^{+}$ & $\mathrm{Ca}^{+2}$ & $\mathrm{Mg}^{+2}$ & \multirow[t]{2}{*}{$\mathrm{Na}^{+2}$} & $\mathrm{~S}$ \\
\hline $\mathrm{ds} / \mathrm{m}$ & Org. & & $1: 2: 5$ & & & & & & \\
\hline $0,23 \mathrm{a}$ & $0,83 \mathrm{a}$ & $0,48 \mathrm{a}$ & 7,6 & $61 \mathrm{c}$ & $0,31 \mathrm{a}$ & $3,8 \mathrm{c}$ & $1,4 \mathrm{c}$ & $0,02 \mathrm{a}$ & $5,53 \mathrm{~d}$ \\
\hline \multicolumn{3}{|c|}{$\mathrm{Sb}=\mathrm{Ca}+\mathrm{Mg}+\mathrm{Na}+\mathrm{K}$} & \multicolumn{2}{|c|}{$\mathrm{T}=\mathrm{Sb}+(\mathrm{H}+\mathrm{Al})$} & \multicolumn{5}{|l|}{$\mathrm{V} \%=(\mathrm{S} / \mathrm{T}) \times 100$} \\
\hline $\mathrm{H}^{+} \mathrm{Al}$ & $\mathrm{I}$ & $\mathrm{Al}^{+++}$ & Sat.Ca $^{+2}(\%)$ & $\begin{array}{l}\text { Sat.Mg }{ }^{+2} \\
(\%)\end{array}$ & Sat.Na ${ }^{+}(\%)$ & & \multicolumn{2}{|c|}{ Sat. $\mathrm{K}^{+}(\%)$} & \\
\hline 0,00 & 5,53 & 0,00 & $68,7 \mathrm{c}$ & $25,3 \mathrm{a}$ & $0,4 \mathrm{a}$ & & \multicolumn{2}{|l|}{$5,6 \mathrm{a}$} & \\
\hline
\end{tabular}

a- baixo, b- médio, c- alto d- muito alto. Embrapa (2012). 
A exploração agrícola provoca alterações significativas nas características do solo que, dependendo do manejo, podem contribuir para aumentar ou diminuir sua capacidade produtiva (Faria et al., 2003). Nas regiões semiáridas, além do fornecimento de água, a melhoria da fertilidade do solo é essencial para aumentar a produção de biomassa, a eficiência do uso da água e também melhorar a qualidade do solo (Bernardi et al., 2007).

Segundo Silva e Araújo (2005) os solos submetidos a cultivos irrigados, normalmente sofrem alterações de ordem química, física e biológica num tempo relativamente curto e em uma intensidade que varia em função da qualidade e quantidade da água aplicada.

As curvas de retenção de água no solo obtidas com os tensiômetros no laboratório, determinadas por secamento e umedecimento (Figura 3), observa-se que o solo em processo de secamento reteve maior quantidade de água que em processo de umedecimento, fenômeno este conhecido por histerese.
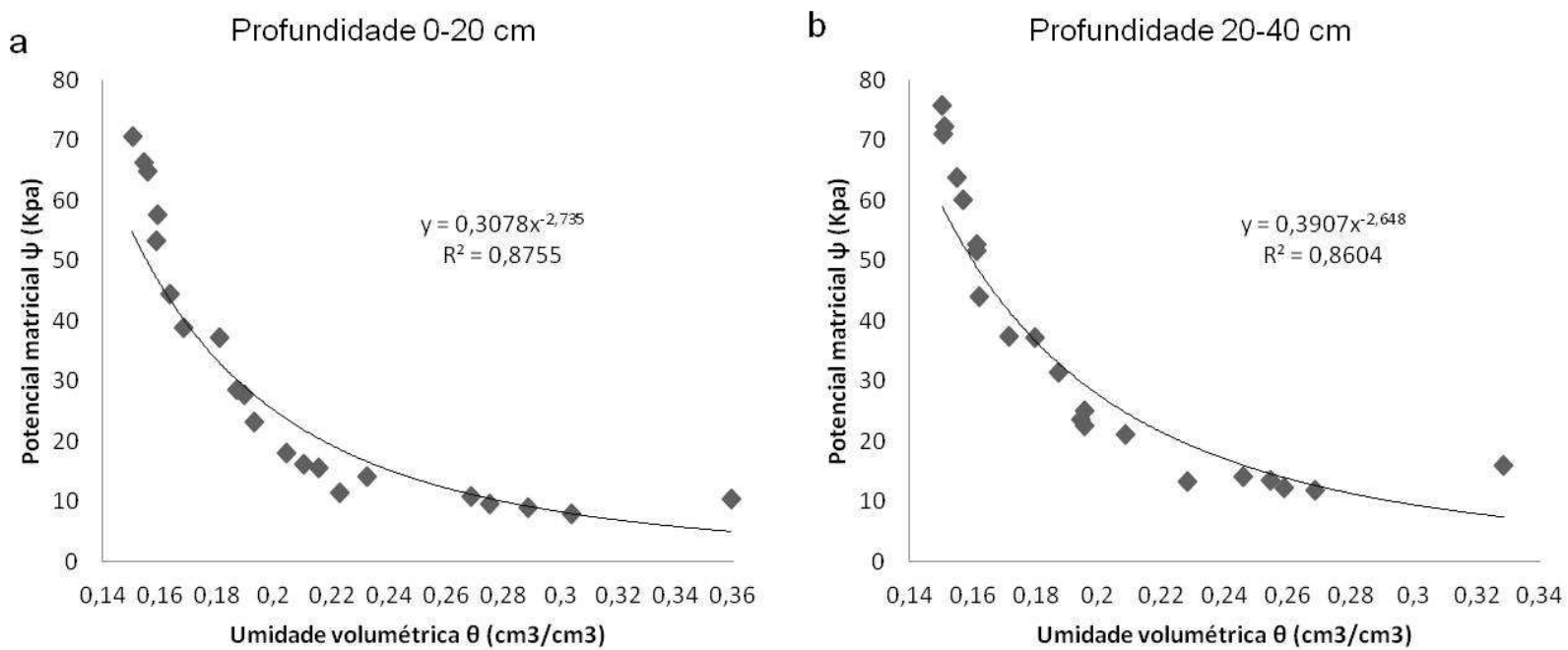

Figura 3. Determinação da curva de retenção de água no solo nas profundidades de $0-20$ (a) e 20-40 (b) por umedecimento e secamento obtidas pelo método da tensiômetria em laboratório.

A capacidade de campo do solo foi determinada quando o potencial matricial chegou a $-10 \mathrm{kpa}$ com umidade volumétrica de $0,22 \mathrm{~cm}^{3} / \mathrm{cm}^{3}$ nas profundidades de $0-20 \mathrm{~cm}$ e 20-40 $\mathrm{cm}$. O Nível Crítico de Umidade (UC) representa o limite para que a redução da umidade do solo não prejudique significativamente à cultura, este nível está entre a capacidade de campo (CC) e o Ponto de Murchamento (PM), que foi obtido nos intervalos de 27 a $66 \mathrm{Kpa}$ com uma umidade volumétrica 0,18 a $0,15 \mathrm{~cm}^{3} / \mathrm{cm}^{3}$, e 31 a $72 \mathrm{Kpa}$ com uma umidade volumétrica 0,18 a $0,15 \mathrm{~cm}^{3} / \mathrm{cm}^{3}$, nas profundidades de $0-20$ e $20-40 \mathrm{~cm}$ de profundidade, respectivamente.

De acordo com os dados a lâmina de água disponível no solo é de $36,6 \mathrm{~mm}$ na profundidade de $0-20 \mathrm{~cm}$ e $69 \mathrm{~mm}$ para a profundidade de $20-40 \mathrm{~cm}$.

Os dados obtidos em campo para determinação da curva característica de umidade do solo (Figura 4) apresentaram tensões com valores inferiores aos das curvas de umidade de solo determinadas em laboratório (Figura 3). 

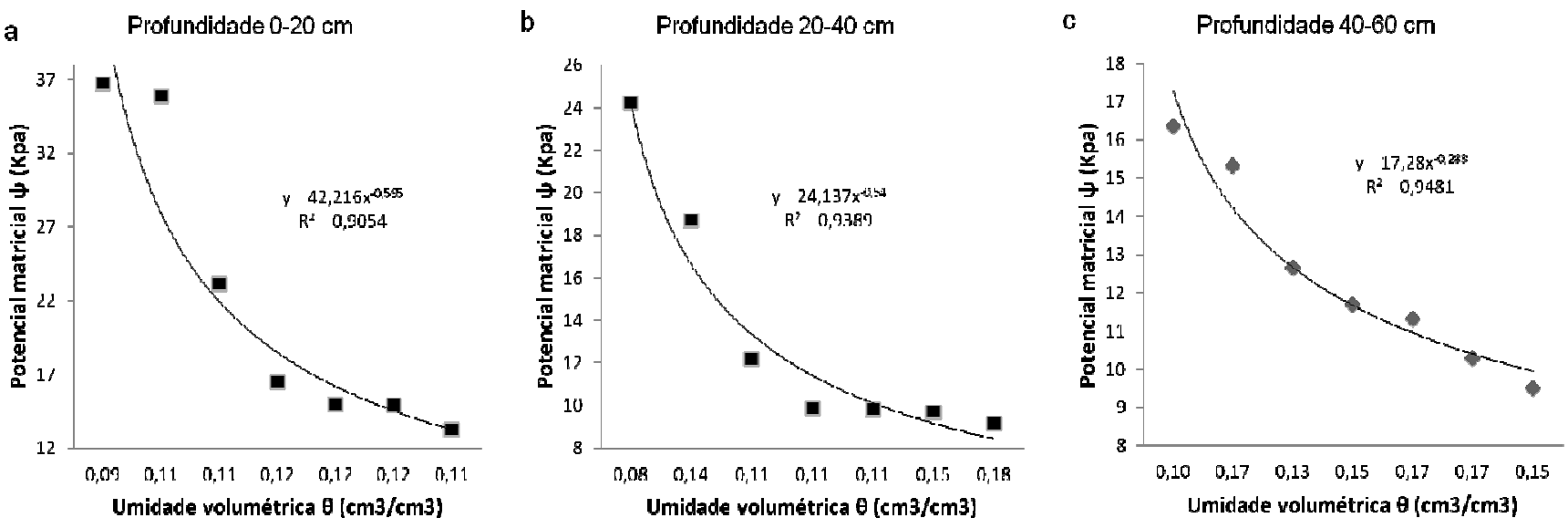

Figura 4. Curvas de retenção de água no solo nas profundidades de 0-20 (a); 20-40 (b) e 4060 (c) obtidas através de tensiômetros instalados em campo.

A umidade volumétrica $\left(\mathrm{cm}^{-3} \mathrm{~cm}^{-3}\right)$ variou pouco nas camadas do solo $0-20 ; 20-40$ e 40-60 cm de profundidade, com valores médios de 0,0341;0,0996 e $0,0762 \mathrm{~cm}^{-3} \mathrm{~cm}^{-3}$, chegando ao potencial matricial máximo de 36,72; 24,23 e 16,35, respectivamente.

Segundo Orlov (1985), o potencial matricial pode variar entre 15 a $25 \mathrm{kPa}$ para solos arenosos concordando com os resultados encontrados neste trabalho.

A capacidade de campo (CC) nas profundidades 0-20; 20-40 e 40-60 cm, atingiu potenciais matriciais de 17; 12 e $11 \mathrm{Kpa}$, respectivamente. Esses valores dependem da estabilização do movimento de drenagem e é influenciado pela textura, estrutura, profundidade e uniformidade do solo.

Observa-se na tabela 2 que a posição da gema na porção intermediária do ramo apresentou um percentual de gemas férteis de $88 \%$, sendo superior às demais posições.

Tabela 2. Percentagem média de fertilidade de gema potencial da cv. Superior Seedless, analisados antes da poda de produção, ao longo das varas.

\begin{tabular}{ll}
\hline Posição da gema dentro do ramo & Médias de fertilidade (\%) \\
\hline Inicial (0-5) & $64,00 \mathrm{~b}$ \\
Intermediária (6-10) & $88,00 \mathrm{a}$ \\
Apical (11-15) & $72,00 \mathrm{a} \mathrm{b}$ \\
CV (\%) & 27,91 \\
\hline
\end{tabular}

Médias seguidas pela mesma letra não diferem entre si pelo Teste Tukey $(\alpha<0,05)$

Observa-se pelo teste de médias que o número de cachos nas diferentes tensões aplicadas (Tabela 3), não apresentou diferença significativa. Havendo um consumo pela testemunha no período crítico de crescimento de fruto de aproximadamente $280 \mathrm{~mm}$ de água nos últimos 40 dias do ciclo de produção da videira, enquanto que as plantas submetidas à tensão de $-30 \mathrm{kPa}$ no mesmo período e fase, o consumo foi de $90 \mathrm{~mm}$, havendo uma redução de $68 \%$ na lâmina de irrigação. Além da economia no volume de água aplicado, há uma menor percolação dos nutrientes aplicados na cultura, bem como uma redução no custo produção da videira.

Para Ávila Netto et al. (2000), a restrição hídrica durante as duas primeiras fases de crescimento das bagas pode reduzir o tamanho dos frutos e atrasar o seu amadurecimento, o que não foi observado neste trabalho. Os resultados observados indicaram que com a redução da lâmina de irrigação obteve-se o mesmo número total de cacho por planta, minimizando 
custo ao produtor, uma vez que com uma redução de $20 \%$ no uso da água para irrigação obteve-se o mesmo número de cachos.

Segundo Netzer et al. (2009) estratégias de imposição do deficit hídrico só devem ser adotadas se a economia de água não tiver impacto negativo na produtividade e na qualidade da uva. Portanto, podemos aplicar um maior intervalo de tempo no turno de rega, o qual acarretaria uma maior economia de água e energia, minimizando assim, os custos de manejo da cultura.

Segundo Marinho et al. (2009) lâminas de irrigação têm efeitos diferentes sobre o número e o peso total de cachos por planta, produtividade e eficiência de uso de água da uva 'Superior Seedless', apenas aos cinco dias antes da colheita.

Bassoi et al., (2011) estudando a influência de manejos de irrigação sobre 'Syrah' observou que a prática do manejo de irrigação com déficit hídrico, a partir da fase fenológica de cacho fechado, alterou o comportamento ecofisiológico e reduziu a massa individual de cachos, a massa e o volume de 100 bagas, e a acidez total titulável do mosto. Contudo, o teor de solido solúveis totais e o $\mathrm{pH}$ do mosto não foram influenciados pelos tratamentos com déficit hídrico e déficit hídrico controlado.

Tabela 3. Médias de números de cachos em deferentes tensões $(-30,-50,-70 \mathrm{Kpa})$ na cv. Superior Seedlees, analisadas no período de produção das plantas.

\begin{tabular}{ll}
\hline Tratamentos & Números de cachos \\
\hline Tensão de 30 Kpa (QM) & $66,50 \mathrm{a}$ \\
Tensão de 50 Kpa (QM) & $69,33 \mathrm{a}$ \\
Tensão de 70 Kpa (QM) & $65,00 \mathrm{a}$ \\
Testemunha (QM) & $69,00 \mathrm{a}$ \\
\hline
\end{tabular}

Médias seguidas pela mesma letra não diferem entre si pelo Teste Tukey $(\alpha<0,05)$

Observa-se na Figura 5 que as plantas submetidas às diferentes tensões de água no solo apresentaram percentual de açúcares totais diferenciado, sendo a maior concentração observada em plantas submetidas à tensão de $-50 \mathrm{kPa}$, isso pode esta relacionado ao vigor planta, as condições de clima tropical, especificamente semiárido, a redução hídrica do solo, que promove estresse na planta alterando metabolismo do vegetal, com isso há um acúmulo maior de ácido abscísico e etileno, sendo estes promotores do envelhecimento dos tecidos vegetais, o que pode acarretar em uma baixa atividade metabólica.

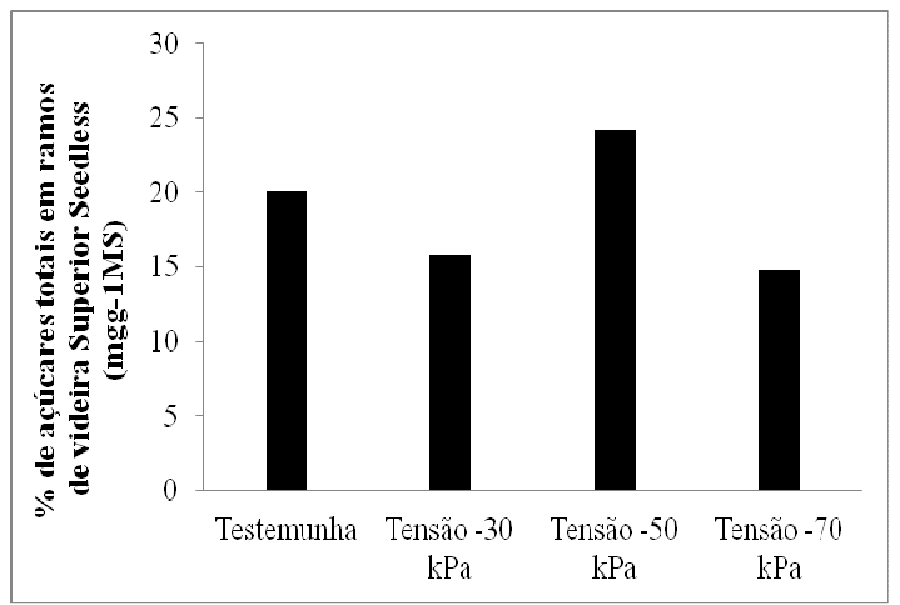

Figura 5. Percentuais açúcares totais em ramos de videira 'Superior Seedless' submetidas às tensões de $-30,-50$ e $-70 \mathrm{kPa}$. 
Embora as plantas submetidas à tensão de $-50 \mathrm{kPa}$ apresentarem maior acúmulo de carboidratos, essa energia pode ser transformada em outros açúcares, o que pode comprometer as reservas da planta para o próximo ciclo. Com isso, os ramos ficam sem condições de concluir completamente o seu desenvolvimento (armazenar e diferenciar as gemas florais) ou sua maturação, nesse caso, o equilíbrio é devido a uma variação das relações hormonais, as quais decidem o deslocamento e a distribuição dos açúcares na planta; se os hormônios responsáveis pelo crescimento (auxina, citocinina, giberelina) prevalecem nos ápices, isto faz desses centros privilegiados de utilização dos açúcares. Segundo Taiz e Zeiger (2009) o açúcar em abundância promove o crescimento e a estocagem de carboidratos nos drenos.

Apesar das plantas submetidas à tensão de $-30 \mathrm{kPa}$ apresentaram menor acúmulo de carboidratos quando comparada a tensão de $-50 \mathrm{kPa}$; estas estavam em um menor estresse hídrico, interferindo menos no metabolismo dessas plantas.

Como a videira é uma planta extremamente exigente quanto aos níveis de carboidratos para eficiência e qualidade na formação de seus frutos, o armazenamento e a utilização de carboidratos dependem tanto do estado de crescimento do ramo quanto da quantidade de uva produzida.

Portanto, a disponibilidade hídrica do solo é um fator muito importante para o aumento das bagas, chegando a ser diretamente proporcional à quantidade de água disponível para a planta.

\section{CONCLUSÕES}

O manejo de água solo a $0,-30,-50,-70 \mathrm{kPa}$ não promoveu diferenças significativas quanto ao número total de cachos por planta.

A tensão de $-30 \mathrm{kPa}$ promoveu uma redução na lâmina de irrigação de $68 \%$, acarretando uma redução no manejo de produção da cultura.

O percentual de carboidratos nos ramos da videira 'Superior Seedless foi influenciado pelas diferentes tensões de água no solo.

\section{REFERÊNCIAS BIBLIOGRÁFICAS}

ALBUQUERQUE, T.C.S. de. Adubação mineral da videira. Disponível em: http://www.alice.cnptia.embrapa.br/bitstream/doc/154524/1/OPB733.pdf. Acessado em 02 set 2012

ÁVILA NETTO, J.; AZEVEDO, P.V. de; SILVA, B. B. da; SOARES, J. M.; TEIXEIRA, A.H. de C. Exigência hídrica da videira na Região do Submédio São Francisco. Pesquisa Agropecuária Brasileira, v.35, p.1559-1566, 2000.

BASSOI, L. H.; GONÇALVES, S. de. O.; SANTOS, A. R. L. dos.; SILVA, A. J.; LIMA, C. M. A. Influência de manejos de irrigação sobre aspectos de ecofisiologia e de produção da videira cv. Syrah / Paulsen 1103. Irriga, Botucatu, v. 16, n. 4, p. 395-402, 2011. 
BERNARDI, A.C. C.; TAVARES, S. R. L.; CRISÓSTOMO, L. A. Alteração da fertilidade de um neossolo quartzarênico em função da lixiviação de nutrientes. Irriga, Botucatu, v. 12, n. 4, p. 429-438, 2007.

CONCEIÇÃO, M. A. F.; MAIA, J. D. G. CAMARGO, J. D. Estimativa da demanda hídrica da videira durante o primeiro ciclo produtivo em Jales, SP. Revista Brasileira de Fruticultura, Cruz das Almas, v.20, n.1, p.39-44, 1998.

DELOIRE, A.; CARBONNEAU, A.; WANG, Z. P. ; OJEDA, H. Vine and water : a short review. Jounal International Des Scienes de la Vigne et Du vin, Bordeaux, v. 38, n. 1, p. $1-13,2004$.

FERREYRA, R.E.; SELLES, G.; SILVA, H.; AHUMADA, R.; MUÑOZ, I.; MUÑOZ, V. Efecto del água aplicada em lãs relaciones hídricas y productividad de la vid 'Crimson Seedless'. Pesquisa Agropecuária Brasileira, v.41, p.1109-1118, 2006.

INSTITUTO ADOLFO LUTZ. Normas Analíticas do Instituto Adolfo Lutz: Métodos químicos e físicos para análise de alimentos, 3.ed. São Paulo., v.1, p.51-53, 1985.

KLAR, A. E. Irrigação: frequência e quantidade de aplicação. São Paulo: Nobel, 1991. 156p.

LIBARDI, P. L. Dinâmica da água no solo. 2.ed. Piracicaba: o autor. 1999. 501p.

MARINHO, L. B.; RODRIGUES, J. J. V.; SOARES, J. M.; LIMA, M. A. C. de.; MOURA, M. S. B. de.; BRANDÃO, E. O.; SILVA, T. G. F. da.; CALGARO, M. Produção e qualidade da videira 'Superior Seedless' sob restrição hídrica na fase de maturação. Pesquisa Agropecuária Brasileira, Brasília, v.44, n.12, p.1682-1691, dez. 2009.

NETZER, Y.; YAO, C.; SHENKER, M. Water use and the development of seasonal crop coefficients for Superior Seedless grapevines trained to an open-gable trellis system.

Irrigation Science, v.27, p.109-120, 2009.

ORLOV, D. Manejo y control del riego em plantaciones de arboles futales. Ministério de Agricultura de Israel, 1985. 46p. (Servicio de Campo).

RIBEIRO, V. G. et al. Expressão da Fertilidade de gemas da 'Superior Seedless' no município de Petrolina (PE). Revista Caatinga, v.21, p.231-235, 2008.

REICHARDT, K, Capacidade de Campo. Revista Brasileira de Ciência do Solo, Campinas, v.12, p.211-216, 1988.

SANTOS, R.A.; HERNANDEZ, F.B.T.; KONRAD, M.; BRAGA, R.S.; SASSAKI, N. Comportamento do sistema radicular da videira (Vitis vinifera L.), variedade Benitaka, frente ao manejo da irrigação por aspersão sob copa. In: CONGRESSO BRASILEIRO DE ENGENHARIA AGRÍCOLA, 31., 2002, Salvador. Anais... CD-ROM

SENTELHAS, P. C. Aspectos climáticos para a viticultura tropical. Informe Agropecuário, Belo Horizonte, v.19, n.194, p.9-14, out. 1998. 
SERMAN, F.V.; LIOTTA, M.; PARERA, C. Effects of irrigation defi cit on Table grape cv. Superior Seedless production. Acta Horticulturae, n.646, p.183-186, 2004.

SILVA, R. J. L. et al. Efeito da poda antecipada e regime de irrigação nos teores de açúcares em uvas 'Niágara Rosada'. Ciência e Agrotecnologia, v.33, n.3, p.844-847, 2009.

SILVA, D. J.; ARAÚJO, C. A. de S. Agricultura irrigada: a importância da adubação. In: CONGRESSO BRASILEIRO DE CIÊNCIA DO SOLO, 30., 2005, Recife. Anais... Recife: SBCS, 2005. 1 CD-ROM.

SOARES, J. M.; COSTA, F. F. da. Irrigação na cultura da videira. Informe Agropecuário, Belo Horizonte, v.19, n.194, p.58-69, out. 1998.

SOUZA, E.R.; RIBEIRO, V.G.; PIONÓRIO, J.A.de.A. Intensidades de desfolha para qualidade de cachos da videira "Superior Seedless" no 'Submédio' São Francisco. Revista Brasileira de Tecnologia Aplicada nas Ciências Agrárias, Guarapuava-PR, v.5, n.1, p.8798, 2012. 